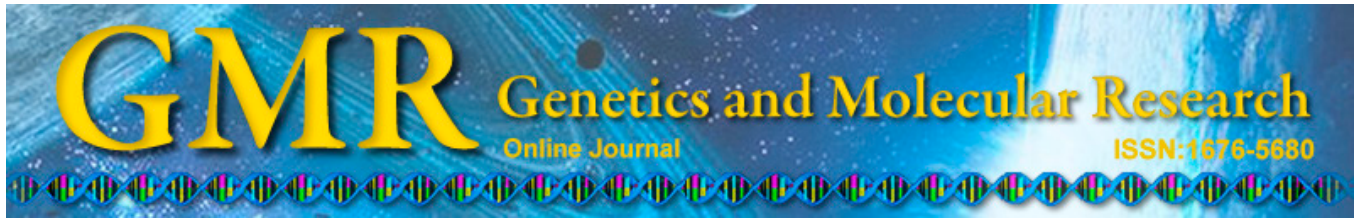

\title{
Isolation and characterization of microsatellite loci from the tick Amblyomma aureolatum (Acari: Ixodidae)
}

M. Ogrzewalska1, M.M. Bajay ${ }^{2}$, K. Schwarcz ${ }^{3}$, S.K. Bajay', M.P.C. Telles, J.B. Pinheiro ${ }^{2}$, M.I. Zucchi ${ }^{5}$, A. Pinter ${ }^{4}$ and M.B. Labruna ${ }^{1}$

${ }^{1}$ Departamento de Medicina Veterinária Preventiva e Saúde Animal, Faculdade de Medicina Veterinária e Zootecnia, Universidade de São Paulo, São Paulo, SP, Brasil

${ }^{2}$ Departamento de Genética,

Escola Superior de Agricultura "Luiz de Queiroz" da Universidade de São Paulo, Piracicaba, SP, Brasil

${ }^{3}$ Departamento de Genética e Evolução e Bioagentes, Universidade de Campinas, Campinas, SP, Brasil

${ }^{4}$ Superintendência de Controle de Endemias, São Paulo, SP, Brasil

${ }^{5}$ Pólo Centro-Sul, Agência Paulista de Tecnologia dos Agronegócios, Campinas, SP, Brasil

${ }^{6}$ Laboratório de Genética e Biodiversidade, Instituto de Ciências Biológicas, Universidade Federal de Goiás, Goiânia, GO, Brasil

Corresponding author: M. Ogrzewalska

E-mail: mogrzewalska@gmail.com

Genet. Mol. Res. 13 (4): 9622-9627 (2014)

Received November 7, 2013

Accepted May 5, 2014

Published November 14, 2014

DOI http://dx.doi.org/10.4238/2014.November.14.6

\begin{abstract}
Amblyomma aureolatum (Pallas) is the main vector of the bacterium Rickettsia rickettsii, the etiological agent of Brazilian spotted fever. This disease is the most lethal human spotted fever rickettsiosis in the world. Microsatellite loci were isolated from a dinucleotide-enriched library produced from A. aureolatum sampled in Southeastern Brazil. Eight polymorphic microsatellites were further characterized among 38 individuals sampled from São Paulo metropolitan region. The number of observed
\end{abstract}


alleles ranged from 2 to 9 , observed heterozygosity was $0.184-0.647$, and expected heterozygosity was $0.251-0.747$. Cross-species amplifications suggested that these loci will be useful for other Amblyomma species.

Key words: Amblyomma aureolatum; Enriched library; Microsatellites; Ticks

\section{INTRODUCTION}

The tick Amblyomma aureolatum (Pallas) is an important vector of the bacterium Rickettsia rickettsii, the etiological agent of Brazilian spotted fever (BSF). BSF is the most lethal human spotted fever rickettsiosis worldwide (Pinter and Labruna, 2006). A. aureolatum has been found to be restricted to the Neotropical region, covering the eastern area of South America from Uruguay to Surinam, including Northeastern Argentina, Eastern Paraguay, Southern and Southeastern Brazil, and French Guiana (Guglielmone et al., 2003). This tick species is typical of the Atlantic rainforest, where optimal conditions including high humidity and cool temperatures are present throughout the year (Pinter et al., 2004).

Individuals of the adult stage of $A$. aureolatum feed chiefly on carnivore species, while immature ticks (larvae and nymphs) prefer to feed on passerine birds and a few rodent species (Guglielmone et al., 2003). Humans are accidental hosts that get infected when bitten by $R$. rickettsiiinfected adult ticks. However, many questions remain regarding the epidemiology of this disease.

Understanding the population genetics of $A$. aureolatum may provide insight into many ecological features of this tick, including reproductive modes and/or strategies of dispersal, population size, and structure, and may contribute to a better understanding of disease ecology (de Meeûs et al., 2007; McCoy, 2008), such as BSF. However, the genetic diversity and population structure of this important tick vector remain unknown because of the absence of appropriate genetic markers. In this study, we isolated and characterized 8 polymorphic microsatellite markers in A. aureolatum and analyzed the population structure and dispersal patterns of this organism. Furthermore, microsatellite markers developed for A. aureolatum were tested for 2 additional important Brazilian tick species: Amblyomma cajennense (F.), another important vector of $R$. rickettsii (Labruna, 2009), and Amblyomma ovale Koch, the vector of another human pathogen, Rickettsia parkeri (Sabatini et al., 2010).

\section{MATERIAL AND METHODS}

Whole A. aureolatum non-engorged females collected in 2010 from domestic dogs of São Bernardo Municipality, State of São Paulo, Brazil (Ogrzewalska et al., 2012) were subjected to DNA extraction using the DNeasy tissue kit (Qiagen; Hilden, Germany) according to the manufacturer protocol. Microsatellites were isolated following an enrichment protocol (Billotte et al., 1999) with modifications. DNA was digested with AfaI (New England Biolabs; Ipswich, MA, USA) and the fragments were ligated to adapters at the $A f a$ I restriction site. The 300-1200-base pair (bp) fragments were selected for and purified using the Quiaquick PCR purification kit (Qiagen). Positive fragments containing microsatellite fragments were selected by hybridization with biotinylated oligonucleotides that were complementary to the repetitive sequence $\mathrm{CT} / \mathrm{GT}$, and were recovered using magnetic beads linked to streptavidine. Microsatellite-rich fragments were amplified by polymerase chain reaction (PCR) and cloned 
into the vector pGEM-T (Prodimol; Biotecnologia; Belo Horizonte, MG, Brazil). Escherichia coli cells were transformed with the plasmids and incubated overnight with ampicillin for selection. The inserts were amplified with the T7 promoter and M13 reverse plasmid vector primers and purified using ExoSAP-IT (GE Healthcare Life Sciences; Little Chalfont, UK) according to the manufacturer protocol. Both strands were sequenced using the Big Dye cycle sequencing kit using ABI 3700 sequencers (Applied Biosystems; Foster City, CA, USA).

For positive clones, we used Oligo 4.0 to design PCR primer pairs that were complementary to the flanking regions of microsatellites that had at least 5 repeat motifs. Primer pairs complementary to sequences flanking the repeat element were designed to amplify unique loci using the Primer 3 software (Rozen and Skaletsky, 2003), and then analyzed using the Oligo Explorer program (Javed et al., 2010) to exclude sequences showing dimer, heterodimer, and hairpin formations. Oligonucleotides located too close to the vector or in regions of low quality sequences were excluded.

Polymorphic microsatellites identified in the present study were further characterized in 38 adult A. aureolatum individuals collected from domestic dogs in Santo André Municipality, State of São Paulo, Brazil (Ogrzewalska et al., 2012). DNA was extracted as described above.

PCRs were optimized and performed in a Mastercycler pro $\mathrm{S}$ vapo.protect ${ }^{\mathrm{TM}}$ thermocycler (Eppendorf; Hamburg, Germany) in $25-\mu \mathrm{L}$ volumes containing $12.5 \mu \mathrm{L}$ DreamTaq Green PCR Master Mix (Sinapse Biotecnologia Ltda; São Paulo, Brazil), $1 \mu \mathrm{L}$ of each primer at $10 \mu \mathrm{M}, 8 \mu \mathrm{L}$ molecular-grade water, and $2.5 \mu \mathrm{L}$ template (approximately $300 \mathrm{ng}$ tick DNA). Reactions were performed under the following conditions: 3 min at $95^{\circ} \mathrm{C}$, followed by 35 (primer 73, 130,12,110), 40 (primer 65, 104, 123), or 45 (primer 113) cycles of $15 \mathrm{~s}$ at $95^{\circ} \mathrm{C}$, $30 \mathrm{~s}$ at the locus-specific annealing temperature (Table 1), and $30 \mathrm{~s}$ at $72^{\circ} \mathrm{C}$; final extension was performed for $5 \mathrm{~min}$ at $72^{\circ} \mathrm{C}$. Amplified products were separated by electrophoresis on a denaturing $7 \%$ polyacrylamide gel and visualized by silver nitrate staining by consecutive exposure to a fixing solution. Each locus was genotyped by direct visualization of the bands in a transilluminator according to the procedure of Sanguinetti et al. (1994). Allele sizes were determined by comparison to a known size (10-bp) ladder (Invitrogen; Carlsbad, CA, USA).

Observed and expected heterozygosities were calculated using Genepop (Raymond and Rousset, 1995). To verify Hardy-Weinberg equilibrium (HWE), Fisher's exact test was performed (Table 1). For linkage disequilibrium, the G test was used. All tests were corrected for multiple comparisons using Bonferroni's correction (Rice, 1989). In addition, amplification of 5 individual adults of $A$. ovale collected in Ubatuba Municipality, São Paulo, and 5 adults of $A$. cajennense collected in the Grande Sertão Veredas National Park, Minas Gerais, were tested with the obtained primers using the PCR conditions described above.

\section{RESULTS AND DISCUSSION}

A total of 86 clones were randomly chosen from the library and tested for satellite sequences using the PCR approach. From these samples, 34 (39.5\%) tested positive for microsatellite fragments. Among the clones with microsatellites, $20(58.8 \%)$ had microsatellite fragment sequences and a flanking region of adequate size for the design of forward and reverse primers. Twelve loci were discarded because they were monomorphic or showed a high incidence of nonspecific bands. Finally, 8 polymorphic microsatellites were identified in the present study (Table 1). The number of observed alleles in the $38 \mathrm{~A}$. aureolatum individual ticks ranged from 2-9, with observed heterozygosities $\left(H_{\mathrm{O}}\right)$ of $0.184-0.647$. Expected hetero- 


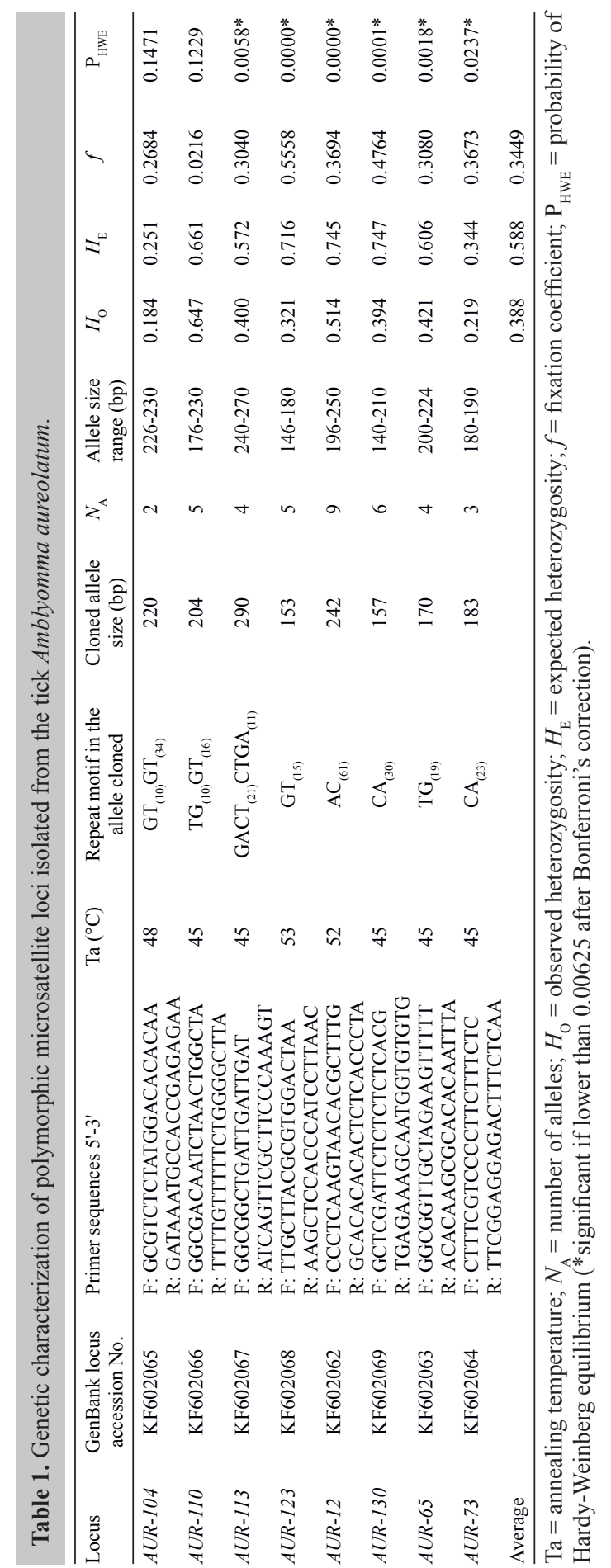


zygosity $\left(H_{\mathrm{E}}\right)$ varied from $0.251-0.747$. We did not observe disequilibrium linkage between any pairs of loci $(\mathrm{P}>0.05)$. Six loci presented deviation from the expected frequencies in HWE $(\mathrm{P}<0.05$; Table 1) and the inbreeding coefficient $(f)$ varied from 0.022-0.560 (average 0.350 ); thus, the departure from HWE in most loci was the result of the high-value inbreeding coefficient (Hataway et al., 2011) rather than the effect of null alleles.

Cross-species amplification of the 8 loci was scored as positive (in the expected size range) for $A$. ovale and A. cajennense. These microsatellite loci may be useful for genetic studies of these species and likely for other Amblyomma species that require testing in further studies.

For ticks (Ixodida), microsatellite markers have been developed and tested only for the genera Ixodes (Delaye et al., 1998; McCoy and Tirard, 2000), Bothriocroton (Guzinski et al., 2008), and Rhipicephalus (Chigagure et al., 2000; Kanduma et al., 2012); therefore, this is the first study to develop such markers for the genus Amblyomma.

Microsatellite markers developed for A. aureolatum should enable the examination of a diverse range of questions related to tick dispersal among hosts between BSF-endemic and non-endemic areas. This data will be valuable for examining the evolution of local adaptation in this host-parasite system and for examining the epidemiology of BSF and other Amblyomma-borne diseases.

\section{ACKNOWLEDGMENTS}

Research supported by the Fundação de Amparo à Pesquisa do Estado de São Paulo (FAPESP) (grants \#2009/52892-7; \#2010/50113-8). We thank Professor Anete Pereira de Souza (Universidade Estadual de Campinas) for technical support in construction of the microsatellite-enriched library.

\section{REFERENCES}

Billotte N, Lagoda PJL, Risterucci AM and Baurens FC (1999). Microsatellite-enriched libraries: applied methodology for the development of SSR markers in tropical crops. Fruits 54: 277-288.

Chigagure NN, Baxter GD and Barker SC (2000). Microsatellite loci of the cattle tick Boophilus microplus (Acari: Ixodidae). Exp. Appl. Acarol. 24: 951-956.

de Meeûs T, McCoy KD, Prugnolle F, Chevillon C, et al. (2007). Population genetics and molecular epidemiology or how to "debusquer la bête". Infect. Genet. Evol. 7: 308-332.

Delaye C, Aeschlimann A, Renaud F, Rosenthal B, et al. (1998). Isolation and characterization of microsatellite markers in the Ixodes ricinus complex (Acari: Ixodidae). Mol. Ecol. 7: 360-361.

Guglielmone AA, Estrada-Pena A, Mangold AJ, Barros-Battesti DM, et al. (2003). Amblyomma aureolatum (Pallas, 1772) and Amblyomma ovale Koch, 1844 (Acari: Ixodidae): hosts, distribution and 16S rDNA sequences. Vet. Parasitol. 113: 273-288.

Guzinski J, Saint KM, Gardner MG, Donnellan SC, et al. (2008). Permanent genetic resources: Development of microsatellite markers and analysis of their inheritance in the Australian reptile tick, Bothriocroton hydrosauri. Mol. Ecol. Resour. 8: 443-445.

Hataway RA, Reed DH and Noonan BP (2011). Development of 10 microsatellite loci in the wolf spider Arctosa sancterosae (Araneae: Lycosidae). Conserv. Genet. Resour. 3: 271-273.

Javed AA, Muthusamy A and Kuulaasmaa T (2010). Oligo analyzer version 1.5. Available at [http://www.genelink.com/ tools/OEreg.asp]. Accessed August 17, 2010.

Kanduma EG, Mwacharo JM, Sunter JD, Nzuki I, et al. (2012). Micro- and minisatellite-expressed sequence tag (EST) markers discriminate between populations of Rhipicephalus appendiculatus. Ticks. Tick. Borne. Dis. 3: 128-136.

Labruna MB (2009). Ecology of rickettsia in South America. Ann. N. Y. Acad. Sci. 1166: 156-166.

McCoy KD and Tirard C (2000). Isolation and characterization of microsatellites in the seabird ectoparasite Ixodes uriae. Mol. Ecol. 9: 2213-2214. 
McCoy KD (2008). The population genetic structure of vectors and our understanding of disease epidemiology. Parasite 15: 444-448.

Ogrzewalska M, Saraiva DG, Moraes-Filho J, Martins TF, et al. (2012). Epidemiology of Brazilian spotted fever in the Atlantic Forest, State of São Paulo, Brazil. Parasitology 139: 1283-1300.

Pinter A, Dias RA, Gennari SM and Labruna MB (2004). Study of the seasonal dynamics, life cycle, and host specificity of Amblyomma aureolatum (Acari: Ixodidae). J. Med. Entomol. 41: 324-332.

Pinter A and Labruna MB (2006). Isolation of Rickettsia rickettsii and Rickettsia bellii in cell culture from the tick Amblyomma aureolatum in Brazil. Ann. N. Y. Acad. Sci. 1078: 523-529.

Raymond M and Rousset F (1995). Genepop (version 1.2): population genetics software for exact tests and ecumenicism. J. Hered. 86: 248-249.

Rice WR (1989). Analyzing tables of statistical tests. Evolution 43: 223-225.

Rozen S and Skaletsky HJ (2003). Primer 3. Code. Available at [http://www-genome.wi.mit.edu/genome_software/other/ primer3.html]. Accessed August 17, 2010.

Sabatini GS, Pinter A, Nieri-Bastos FA, Marcili A, et al. (2010). Survey of ticks (Acari: Ixodidae) and their Rickettsia in an Atlantic rain forest reserve in the State of São Paulo, Brazil. J. Med. Entomol. 47: 913-916.

Sanguinetti CJ, Dias NE and Simpson AJ (1994). Rapid silver staining and recovery of PCR products separated on polyacrylamide gels. Biotechniques 17: 914-921. 